\title{
الأساليب الإنشائية في الأربعين النووية
}

\section{Muammar Ahsanul Hilmar}

Institut Agama Islam Negeri Palu, Indonesia

Jl. Diponegoro No. 23, Lere, Kec. Palu Barat, Kota Palu, Sulawesi Tengah, 94221, Indonesia Corresponding E-mail: muammarahsanul@gmail.com

\begin{abstract}
This study aims to describe the secrets contained in the words of the Prophet Muhammad peace be upon him, especially in terms of structuralism in the choice of words spoken from his oral Muhammad peace be upon him, because everything that is spoken from the oral of the Prophet Muhammad is a revelation that is absolute to believe, then in terms of fluency this is a treasure in the branch of balaghah science. This study was library research with inductive approach, where this method focuses on the words of the Prophet Muhammad that written in the Al 'Arbai'in An Nawaiyah book, and also the structural techniques that researched in this study only focuses on a few form of words that is al amr (command word), an nahyu (prohibition word), al istifham (question word), an nidaa (call word). The findings of this study are the words os the Prophet Muhammad that written on Al 'Arbai'in An Nawaiyah book contain many forms of structural techniques with their respective objectives and purposes, example is the word (يُا مُحَمَّدُ in hadith number 2 is included in the category of an nidaa (calling words), which in balaghah science functions to call someone who is some distance away from the speaker, and also another function is a call of honor to someone who has a higher rank than the speaker.
\end{abstract}

Keywords: structuralism, techniques, balaghah, al 'arbai'in an nawawiyah

\begin{abstract}
Abstrak
Penelitian ini bertujuan untuk meneliti lebih dalam tentang kefasihan serta strukturalisme kata-kata yang terucap dari lisan sebaik-baik manusia yaitu Rasulullah Shallallahu 'Alaihi Wasallam, baik yang terlihat secara langsung maupun yang tersirat. Karena kata-kata yang terucapkan dari Rasulullah adalah sebuah wahyu yang bersifat mutlak sehingga hal ini merupakan perbendaharaan yang penting dalam ilmu Balaghah. Tujuan penelitian ini adalah untuk mengungkapkan rahasia-rahasia yang terkandung dalam kata-kata yang diucapkan oleh Rasulullah khususnya dari struktur pemilihan kata beliau Sallallahu 'Alaihi Wasallam. Penelitian ini merupakan kajian pustaka dengan pendekatan induktif. Dimana metode ini berpusat pada perkataan Rasulullah yang tertulis dalam kitab al arba'in an nawāwiyyah dan juga tidak semua uslub insyāiyyah masuk kedalam penelitian ini tetapi hanya terbatas pada bentuk kata al amru (perintah), an nahyu (larangan), al istifham (pertanyaan), an nidā (panggilan). Hasil dari penelitian ini menunjukkan bahwa perkataan Rasulullah Shallallahu 'Alaihi Wasallam yang ada dalam kitab al arba'in an nawāwiyyah banyak yang mengandung uslub insyāiyyah dengan tujuan dan maksud masing-masing baik dari al amru, an nahyu, al istifham, ataupun an nidā salah satu contohnya adalah perkataan yang ada di hadist ke 2 yaitu (يَا مُحَمَّد yang memiliki arti "wahai Muhamad", adalah kategori dari kata an nidā (panggilan) yang dalam ilmu Balaghah digunakan untuk memanggil seseorang yang berjarak agak jauh dari kita, dan juga kata an nidā memiliki fungsi yang lain yaitu sebagai panggilan kehormatan kepada seseorang yang memiliki kedudukan lebih tinggi dari yang memanggil.
\end{abstract}

Kata Kunci: strukturalis, tehnik, balaghah, al 'arbai'in an nawawiyah 
في الكلام ا لأدبيّ الرفيع، وتربية القدرة على فهم

النصوص الجميلة الراقية، والقدرة على محاكاة

بعضها في إنشاء الكلام، والقدرة على الإبداع

والابتكار لدى الذين يملكون في فطرهم الاستعداد

لشيء من ذلك. وليس الغرض من دراسة هذه الفنون

والعلوم والمذاهب والنصوص، الجمودَ في قوالِبِ ما

استتُخْرج من العناصر الجمالية، وما وُضع من قواعد،

دون اكتساب الإحساس المرهف بمواطن الجمال،

لتقديم الأفكار، وصياغة الكالام صياغةً أدبيّة بليغة. 2

إن علوم البلاغية من أجل العلوم العربية

وأرفعها قدرا، فبها يبيّن مقاصد الكلام، والكلام

ينقسم إلى قسمين الخبر والإنشاء. الإِنشاء في اللّغة

هو الإبداع والابتداء، وكلٌّ من ابتدأ شيئاً فقد أنشأه.

وأما الإنشاء اصطلاحا هو الكلام الذي لا ينطبق

عليه تعريف الخبر، ولدى تحليل حقيقته أقول: هو الكلام الذي يَتَققَّفُ تحقُقٌُ مدلوله على النُّطقِق به،

كالأمْرِ والنهي، والدّعاء، والاستفهام، والمدح والذّم،

وإنشاء العقود التّي يتمّ تحقُُعُها بالنُطق بالْجُحَل الّتي

2 عبد الرحمن بن حسن حَبَّكَة الميداني الدمشقي، البلاغة العربية،
البلاغة بفنونها الثلاثة "المعاني - البيان -

البديع" وسائر الفنون الأدبية التي نبَّه عليها أدباء

العرب، وكذلك سائر المذاهب الأدبيّة المستوردة من

الشعوب غير العربيّة ليست إلاًّ بحوثاً وتتبُّعاتٍ

لاكتشاف عناصر الجمال الأدبيّ في الكلام،

ومحاولات لتحديد معالمها، ووضع بعض قواعدها،

دُون أن تستطيع كلهُ هذه البحوثِ والدّراساتِ جَمْع

كلِّ عناصر الجمال الأدبيّ في الكامام، أو استقصاءها، واكتشاف كلّ وجوهها. فالجمال كثيراً ما يتذوّقه الحسّ الظاهر والشعور الباطن، دون أن يستطيع الفكر تحديد كلّ العناصر التي امتلكت استحسانه وإعجابه، وإنْ عرف منها الشيء الكثير، واستطاع أن يُفْرِهَه ويُحَدِد معالمه. 1 والْغَرَضُ من عرض الباحثين لفنون البلاغة وعلومها، وللمذاهب الأدبيّة المختلفة، ولأمثلة الأدبيّة الراقية المقرونةِ بالتحليل الأدبي والبلاغي، تَبْبيةُ القدرة على الإِحساس بعناصر الجمال الأدبيّ 1 عبد الرحمن بن حسن حَبَّكَة الميداني الدمشقي، البلاغة العربية،

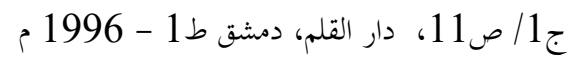


Al Bariq : Jurnal Pendidikan Bahasa Arab, 1, (2), 2020, 63-74

تَكُلُّ عليها، مثل: بِعتنُك - اشتريتُ منك - زوَّجتُكُك وإبراز الأساليب الإنشائية في أقوال رسول الله صلى - أنتِِّ طالق - أعتقتُكَّ. 3و الإنشاء في الجملة الله عليه وسلم حيث أنه أفصح العرب، حتى يتضح على الطلاب العلم بصفة عامة، وعلى الطلاب اللغة الإِنشائية ينقسم إلى قسميْن:

العربية بصفة خاصة.

هناك عدد كبير من الدراسات والبحوث

القسم الأول: الإنشاء غير الطلبي، وهو ما لا السابقة المرتبطة بالبلاغة والأساليب الإنشائية، وهي يستدعي مطلوباً، إلاًّ أنَّه يُنْشِىءُ أمراً مرغوباً في إنشائه، نحو قوله تعالى : إنََّّمَا أَمْهُهُ إذِاَ أََرَادَ شَيْيًَا أَنْ مفيدة لتحديد مركزية هذه الدراسة، ومن تلك يَقُولَ لَهُ كُنْ فَيَكُون

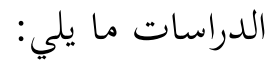

1. دراسة مقدّمة لنيل درجة الماجستير في القسم الثاني: الإنشاء الطلبي. البلاغة والنقد، بعنوان: (أساليب البيان المتكلّم وقت الطلب، ويكون الإنشاء بأنواع من وأثرها في تأدية المعاني في تفسير ضياء الكام: "الأمر - النهي - النداء - التمنّي والترجّي النيرين لأحمد دم سوكون) بجامعة إفريقيا

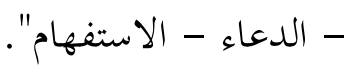
العالمية كلية الآداب قسم اللغة العربية، إعداد الطالب: فودي دكري، إشراف: الدكتور / ياسر عبد المطلب أحمد، 1435

$$
\text { هـ - 2014 م }
$$


Al Bariq : Jurnal Pendidikan Bahasa Arab, 1, (2), 2020, 63-74

1. ما يعود على الباحث في بلاغة أقوال رسول

الله صلى الله عليه وسلم من نفع عظيم في

جانب التحصيل العلمي، حيث يقوي

أسلوبه، و يستقيم لسانه و يهذب بيانه، و

كان أحاديث رسول الله من حسن شاهد

في البلاغة، كما عرفنا غيره يعني من مصادر

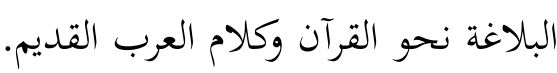

2. 2 إن الإنشاء أحد شقي الكلام، وهذا الشق

يضم المباحث البلاغية التي فصلت في

جملتها وأنواعها، من الأمر والنهي،

والإستفهام والنداء، وغير ذلك من المباحث

$$
\text { البلاغية في الإنشاء. }
$$

3. يريد الباحث أن يفصل النظر والبحث في

الأساليب الإنشائية حيث وجد الباحث مِن

غيره مَن صرفوا جلّ أنظارهم في الخبر،

وبحثوا في الإسناد الخبري، وفصلوا في

$$
\text { مسائله. }
$$

4. الوقوف على آراء علماء البلاغة في بيان عن

الأسلوب الإنشائية الواردة في أحاديث

رسول الله صلى الله عليه وسلم.
انتطلاقا مما سبق، تبين أن الدراسة

السابقة تختلف عن الدراسة الحالية بشكل كلي من

حيث الخلفيات واختلاف الظروف ومجتمع

البحث. والجديد في هذه الدراسة هو تناولها تحليل

الأساليب الإنشائية من حيث الكتاب الأربعين النووية

للإمام النووي. وهذا يختلف تماما عما سبق عرضه

عن - من الدراسة السابقة.

وتظهر أهمية هذا الموضوع في الآتي:

1. تحليل الأساليب الإنشائي التي وردت في

أقوال رسول الله صلى الله عليه وسلم.

2. صدور التحليل والدراسة على موطن

الأسلوب الإنشائي في الأمر، والنهي،

والإستفهام، والنداء، من أقوال رسول الله

صلى الله عليه وسلم.

3. المشاركة في سعي فهم أسرار البلاغية

ونماذجها الواردة في أقوال رسول الله صلى

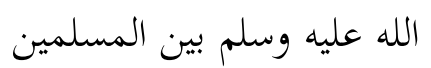

من الأسباب الرئيسية التي دافعت الباحث

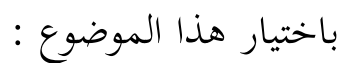


Al Bariq : Jurnal Pendidikan Bahasa Arab, 1, (2), 2020, 63-74

بالقراءة والاطلاع ثم الكتابة بالاعتماد على تلك

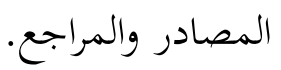

إن مصادر البيانات في هذا البحث على

شكل الملاحظات المخزنة في كتب التراث،

فالتطريقة التي استخدمها الباحث هو طريقة تحليل

$$
\text { المضمون (Content Analysis). }
$$

ويسمى هذا النوع أحيانا ببحوث تحليل

المحتوى أو تحليل الوثائق. 8 وهي كما عرفه ستون

PJ Stone

الحصول على الاستدلالات عن طريق التعرف على

الخصائص المميزة لأي نص من النصوص بطريقة

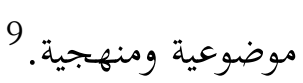

وبوجه التحديل، استخدم الباحث تحليل

Qualitative Content (المضمون الكيفي

Hsieh and Shannon وهو كما عرفه (Analysis

المعجلة. وأول من يستخدم تحليل المضمون في تحليل النصوص هو B B. Bلئ

Content بتركيز التحليل التكراري، Benhard Barelson Analysis In Communication Research, (Newyork: Hafner, 1954) 8 يوسف العنيزي وآخرون، مناهج البحث التربوي بين النظرية والنطبيق، (الكويت: مكتبة الفلاح للنشر والتوزيع، 1999)، 79. 9 أحمد أوزي، تحليل المضمون ومنهجية البحث، (الرباط: الشركة

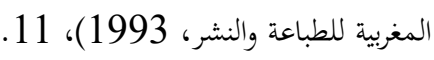

5. التعرف على شواهد الأسلوب الإنشائي

وأسرارها البلاغية وترتيبها من حيث الكثرة.
لهذا البحث مدخل كيفي، وذلك بوصف

الظواهر وصفا دقيقا وفهمها فهما عميقا. 5 يجري

البحث على التدرج في التفكير من الجزئي إلى

الكلي، حيث يبدأ الباحث من البيانات التي جمعها

أو الملاحظات التي قام بها للوصول إلى نتائج معينة،

ويعني هذا أن الفرضيات والنظريات تظهر أو تشتق

من مجموعة البيانات أثناء عملية جمع البيانات.

وبعد تحليلها يعتمد هذا البحث الكيفي على الطريقة

الاستقرائية.6 ونوع البحث هو الدراسة المكتبية،

وهي بحث يعتمد على البيانات المتوفرة في الكتب

والدرويات والمراجع العامة، حيث يبدأ الباحث

5 تائر أحمد غباري، يوسف عبد القادر أبو شندي، خالد محمد أبو شعيرة، البحث النوعي في التربية وعلوم النفس، (عمان: مكتبة

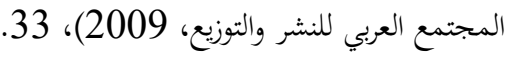

J.W. Cresswell, Qualitative Inquiry \& Research ${ }^{6}$ Design: Choosing Among Five Approaches, Terjemahan: Penelitian Kualitatif dan Desain Riset,

(Yogyakarta: Pustaka Pelajar, 2014), 50.

7 تحليل المضمون هو المدخل في تحليل النصوص حيث يكون

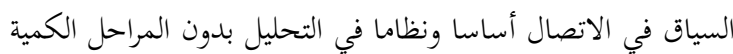


Al Bariq : Jurnal Pendidikan Bahasa Arab, 1, (2), 2020, 63-74

$$
\begin{aligned}
& \text { 2. الالتماس، ويكونُ عادةً من الإنسان لمن هو } \\
& \text { أعلى منه، أو لمساويه } \\
& \text { وإِبْدَاٍِ المشورة } \\
& \text { الحصول عليه، أو فيما هو بعيد المنال } \\
& \text { 5. }
\end{aligned}
$$

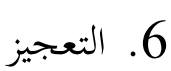

$$
\begin{aligned}
& \text { 7. - - الإهانة }
\end{aligned}
$$

من أمثلة أساليب الأمر التي وجدها

$$
\text { الباحث في الحديث نحو سؤال جبريل عليه السلام }
$$$$
\text { إلى رسول الله صلى الله عليه وسلم عن معنى }
$$$$
\text { الإسلام وذلك في قوله: (أَخْبْرني عَنِ الإسنالام)، }
$$$$
\text { وعن معنى الإيمان والإحسان نحو قوله: (فَأَخْبرنْيْ }
$$$$
\text { عَنِ الإِيْمَانِ) و(فَأَخْبْرنيْ عَنِ الإِحْسَانِ)، ثم معنى }
$$$$
\text { الساعة وإماراتها يعني في قوله: (فَأَخْبِنِي عَنِ }
$$$$
\text { السَّاعَةِ) و(فَأَخْبرْنِيْ عَنْ أَمَارَاتِها). }
$$

of Qualitative Health Research, Vol. 15, No. 9, 2005, Sage Publications, 1278.
الطريقة التي تهدف إلى التفسير الذاتي للبيانات في النصوص من خلال عملية التصنيف والترميز المنظم مع تحديد المواضيع أو الأنماط. 10 إن مدخل هذا البحث يندرج تحت المدخل الكيفي، فأصبحت عملية تحليل البيانات معتمدة على مبادئ هذا المدخل أي يكوم هذا التحليل كيفيا.

\section{الأساليب الإنشائية الطلبي في البلاغة، وبيان من صيغها وأغراضها ثم أمثلتها في الحديث.

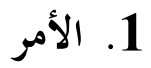
الأمر هو طلَبُ تحقيق شيٍْ ما، مادّيّ أو معنويّ. ولأمر صياغ في البلاغة وهي: "فعل الأمر - المضارع الذي دخلت عليه لام الأمر - اسم فعل الأمر - المصدر النائب عن فعل الأمر". وقد يُسنتَفادُ مِنْ صِيَغ الأَمر التكليفُ الإِلْامِيٌُ بالفعل، ومن صِيَغِ الأمْرِ قد تخرج عن دلآَتها بقرائنِ حاليّة أو قوليّة إلى معانٍ كثيرة، منها ما يلي: 1 ـ الدعاء ويكون عادةً من العبد لربّه

Hsiu-Fang Hsieh and Sarah E Shannon, "Three 10 Approach to Qualitative Content Analysis", Journal 
Al Bariq : Jurnal Pendidikan Bahasa Arab, 1, (2), 2020, 63-74

عليه وسلم: (أُمْرْتُ أَنْ أُقْاَتِلَ النَّاسَ). قال

الشيخ العثيمين رحمه الله تعالى: قوله: أُمْرْتُ

أي أمرني ربي. والأمرُ: طلب الفعل على وجه

الاستعلاء، أي أن الآمر أو طالب الفعل يرى

أنه في منزلة فوق منزلة المأمور، لأنه لو أمر

من يساويه سمي عندهم التماساً، ولو طلب

ممن فوقه سمي دعاءً وسؤالاً. وقوله: أَنْ

$$
\text { أُقَاتِلَ النَّاسَ هذا المأمور به. } 11
$$

ويكون صيغة الأمر هي فعل الأمر، وأما

المعنى أو الغرض يعني المعنى الحقيقي وهو طلب

الفعل على وجه الاستعلاء والتكليفُ الإلْارميُّ بالفعل.

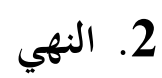

النهي هو طلَب الكفّ عن شيءٍ ما، مادّيّ

أو معنويّ. وقد تدلُّ على النهي صيغةٌ كلامية واحدة

وهي "الفعل المضارع الذي دخلت عليه (لاً)

الناهية". ويستفادُ منْ صيغة النهي هي التكليف

الإلزاميُّ بالترك وعدم الفعل. ومن صِيَغ النهي قد
والصيغة المستخدمة في هذا الحديث هي

صيغة فعل الأمر، وأما غرض الأمر هو الالتماس،

حيث أن جبريل سأل رسول الله صلى الله عليه وسلم أن يخبره بهذه الأمور إرشادا لأصحابه صلى

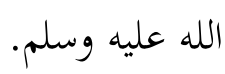

والمثال الآخر نحو أمر الله تعالى إلى

ملائكته في كتابة أرزاق الناس وأجلهم وعملهم وظروف حياتهم، منذ أن كان عمرهم مائة وعشرين

يوما في بطون أمهم. وذلك بقوله تعالى في الحديث القدسي (وَيُوْْهرُ بِأَرْبِعِ كَلِمَاتٍِ: بِكَتْبِ

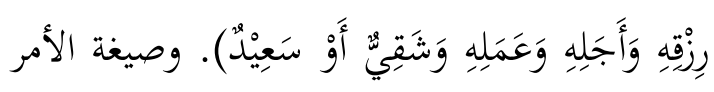
في هذا الحديث هي المصدر النائب عن فعل الأمر فكلمة كَتْبْ بمعنى اكتُُبْ، هي مصدر من فعل كَتَبَ. وغرض الأمر بمعنى الحقيقي وهو طلب الفعل على وجه الاستعلاء والتكليفُ الإلزاميُّ بالفعل.

والمثال الآخر من أساليب الأمر في

الحديث الأربعين النووية هو قوله صلى الله

11 محمد بن صالح بن محمد العثيمين، شرح الأربعين النووية، ص 125-126، دار الثريا للنشر. 
Al Bariq : Jurnal Pendidikan Bahasa Arab, 1, (2), 2020, 63-74

والمثال الآخر من أساليب النهي قوله صلى الله عليه وسلم في حديث أبي هريرة وهي كلمة

(لاَ يَقْبَلُ)، فهذ الكلمة قال بها صلى الله

عليه وسلم إرشادا للمسلمين بأن الله تعالى طيب،

ولا يقبل شيئا إلا طيبا. والغرض من هذا النهي هو

الإرشاد والنصح.

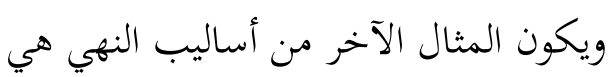

كلمة (لاَ يُؤَمِن) في الحديث الثالث عشر، وهذه

الكلمة نوع من النهي حيث أن صيغتها هي "لا"

الناهية التي دخلت قبل فعل المضارع ، وغرضها

البلاغية هو الإنذار، لأن النهي تفيد تنذير المسلم

على عدم الإيمان لمن لم يحب لأخيه ما يحب

لنفسه.

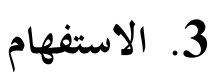

الاستفهام هو من أنواع الإنشاء الطّبي،

والأصل فيه طلَبُ الإفْهامِ والإِعْلاَمِ لتَحْصِيلِ فائدةٍ

عملمِّة مجهولةٍ لدَى الْمُسَفْهِم. للاستفهام طائفةُ من الأدوات، وهي تقع في ثلاثة أقسام:
تخرج عن دلآلتها بقرائنِ حاليّة أو قوليّة إلى معالٍ

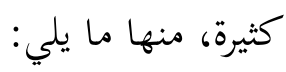
1. الدعاء، ويكون عادةً من العبد لربّه 2. الالتماس، ويكونُ عادةً من الإنسان لمن هو

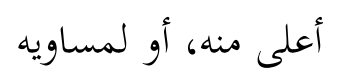

3. الإرشاد، ويكونُ عادةً في مجال النُِّْْ

$$
\text { وإِبْدَاءِ المشورة }
$$

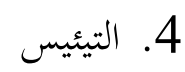

5. - 5 التسوية

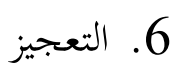

7. التوبيخ والتأنيب والتقريع

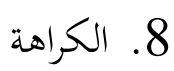

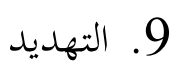

ومن أساليب النهي التي وجدها الباحث في

كتاب الأربعين النووية هي قوله صلى الله عليه وسلم (لاَ يَعْلَمُهُنَّ) بيانا عن أمور المتشابهات. فهذه

الكلمة نوع من النهي، ومعناها البلاغية يعني الإرشاد، وهو التكليف الإِلزاميٌّ بالترك وعدم الفعل إرشادا ونصحا ليبتعد المسلم عن هذه الشبهات. 
Al Bariq : Jurnal Pendidikan Bahasa Arab, 1, (2), 2020, 63-74

من أمثلة الاستفهام في الأربعين النووية هي

كلمة (مَنْ كَانَ) وهي نوع من الاستفهام لوجود أحد

أداة الاستفهام وهي "مَن"، وهذه الأداة يطلب بها

تعيين أحد العقلاء، ومعناها أو غرضها البلاغية يعني

للتذكير، وهو طلب تعيين الفاعل لتذكير على صفة

المسلم المؤمن بالله واليوم الآخر . والمثال الآخر من

أساليب الاستفهام هي كلمة (فَمَنْ كَانَتْ) في

حديث النية المشهور، فأداة الاستفهام في الكلمة

هي "مَنْ" ويطلب بها تعيين أحد العقلاء، ومعناها

البلاغية يعني "للترغيب"، أي ترغيبا للفاعل من

$$
\text { الثواب على الإخلاص في نيته. }
$$

والمثال الآخر من أساليب الاستفهام هي

كلمة (أَأْدُحُلُ الجَنَّة؟) في الحديث الثاني والعشرون،

وأداة الاستفهام هي همزة الاستفهام، وتفيد بهذه

الأداة غرضها الحقيقي يعني التصور والتصديق عن

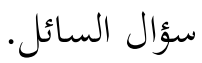

4. الندا

النداء هو طلَبُ الإجابة لأمْرٍ ما بحرف من

حروف النداء يَنُوبُ مَنابِ "أدعو"، وأدوات النداء

ثمان: "أَ - أَيْ - يَا - T - آي - أَيَا - هَيَا - وَا".
القسم الأول: ما يُسْتَفْهَهُ به عن التصوُّر والتصديق،

وهو همزة الاستفهام فقط، وهو حرفه لا يكون له

محلهُ من الإعراب في الجملة.

القسم الثاني: ما يُسَفْهَمُ به عن التصديق فقط وهو

لفظ "هَاْ" وهو حرفٌ أيضاً، لا يكونُ له محلُّ من

الإعراب في الجملة.

القسم الثالث: ما يُسْتَفهَهُم به عن التَّصَوْرُ فقطط، وهي سائر أدوات الاستفهام، وهذه جميعُها أسماء، وهي: "مَا - مَنْ - أَيٌْ - كَمْ - كَيْفَ - أَيْنَ - أَنَّى - مَتَى -

وهنا بعض بيان عن أغراض الإستفهام في البلاغة: 1 ـ الاستفهام المستَعْمَل في الإنْكار

2. الاستفهام المستعمل في التوبيخ والتقريع 3. الاستفهام المستعمل في التقرير

4. الاستفهام المستعمل في التعجُّب أو

\section{التعجيب}

5. الاستفهام المستعمل في الترغيب

6. الاستفهام المستَعْمَلَ في التذكير 
Al Bariq : Jurnal Pendidikan Bahasa Arab, 1, (2), 2020, 63-74

3. التعجب، يُسْتَعْمَلُ النّداءُ في التّعجب برفْع

الصوتِ تعبيراً عمَّا في النفس من حالِّ

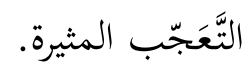

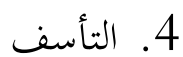

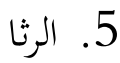

من أمثلة أساليب الندا في الأربعين النووية

هي كلمة (يَا مُحَمَّدُ)، وهذه الكلمة هي دعوة جبريل

عليه السلام إلى رسول الله صلى الله عليه وسلم أثناء

سؤاله وهي نوع من النداء، لوجود أحد أدوات النداء

وهي"يا"، واستعملت "يا" في هذه الكلمة على

معناها الحقيقي، يعني لنداء البعيد - على الراجح -

حكما، وقد يَسْتَعْمِلُ البليغ أيضا أدوات النداء التَّي

للبعيد فينادي بها القريب، لمعنى يريد الإِشارة إليه

على رفع منزلة رسول الله صلى الله عليه وسلم وعلو

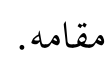

\section{الخحلاصة}

إن النتائج الموجودة من هذا البحث إبانة لنا

بأن الأساليب الإنشائية توجد كثيرا في كلام رسول

الله صلى الله عليه وسلم على ذات المقاصد
- موأمّا "أَيَا - هَيَا - آ" فلنداء البعيد. - ـ وأمّا "يا" فالراجح أنّها موضوعةٌ لنداء البعيد حقِيقةً أو حِكْماً، وقيل مشتركة.

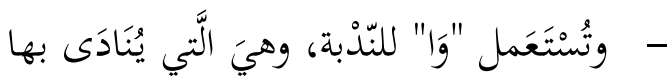
المندوبُ الْمَتَفََّعُع عليه، وتُسْتَعْمَلُ في النُّدْبة أيضاً "يَا" عند أَمْنِ الالتباسِ بالنداءِ الحقيقي.

وقد يخرج النداء عن المعنى الأصليّ الموضوع له، فيُستَتعْمَلُ لدى البلغاء وغيرهم في أغراضٍ أخْرى غير النداء، وهذه الأغراضُ تُفْهَمُ من قرائن الحال أو قرائن المقال، فكلهُ حَرَكَةٍ نفسيَّة ذات مشاعِرَ تَدْفَعُ الإِنسان إلى التعبير عنها بنداء ما بطريقةٍ تلقائية، ولو لم يشعر بأنّ هذا النداء يحقق له مرجوّاً أو مأمولاً أو يدفع عنه مكروها. من أغراض الندا هي: 1. التحسّر، فيسنتعَعْمَل النداء بمدّ الصوت تعبيراً عن تأؤهِه داخِلِيّ في النفس 2. التَّمَنِّي، ويستعمل الندا بمدّ الصّوتِ تَعْبراً عنْ مشاعِرِ النفس المتمنّية أمراً عَسِيرَ المنال أو مُتَعَذِِّرَهُ. 
Hsiu-Fang Hsieh and Sarah E Shannon, "Three Approach to Qualitative Content Analysis", Journal of Qualitative Health Research, Vol. 15, No. 9, Sage Publications, 2005.

Ghabari, Tair Ahmad., et.al. Al-Bahts alNau'I fi al-Tarbiyah wa Ulum alNafs. Amman: Maktabah alMujtama' al_Arabi li al-Nasyr wa al-Tauzi', 2009.

Muhammad bin Saleh al-'Utsaimin, Syarh al-Arba'in an-Nawawiyah, Riyadh: Dar as-Tsurayya li an-Nasyr, 2004.

Al-Unaizi, Yusuf., et.al. Manahij al-Bahts al-Tarbawi baina al-Nadzariyyah wa al-Tathbiq, Kuwait: Maktabah al-Falah li al-Nasyr wa al-Tauzi', 1999.

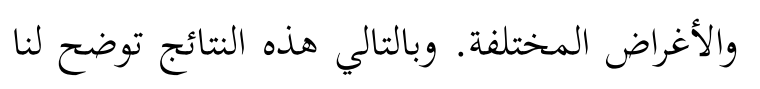

في بلاغة أقوال رسول الله صلى الله عليه وسلم، حيث يقوي أسلوبه، ويستقيم لسانه، ويهذب بيانه. وكان أحاديث رسول الله من حسن شواهد في البلاغة، كما عرفنا غيره يعني من مصادر البلاغة نحو القرآن وكلام العرب القديم.

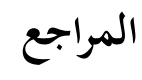

'Abdurrahman bin Hasan, Al-Balaghah al'Arabiyah, Damaskus: Dar alQalam, Beirut: Dar as-Syamiyah, 1996.

Ahmad bin Ibrahim, Jawāhir al-Balaghahfi al-Ma'aniy wa al-Bayan wa alBadi', Beirut: Al-Maktabah al'Asriyyah.

Azwi, Ahmad, Tahlil al-Madmun wa Manhajiyyatu al-Bahts. Rabath: AlSyarikah al-Maghribiyah li alThiba'ah wa al-Nasyr, 1993

Barelson, Benhard. Content Analysis In Communication Research. New York: Hafner, 1954.

Cresswell, J.W. Qualitative Inquiry \& Research Design: Choosing Among Five Approaches, Terjemahan: Penelitian Kualitatif dan Desain Riset. Yogyakarta: Pustaka Pelajar, 2014. 